\title{
Primary Health Care in Post Pandemic Times
}

\section{Mandl Stangl J*}

Stadtbergen Leitershofen, Germany

*Corresponding author: Jorge Mandl Stangl, Stadtbergen Leitershofen, Germany, Email: jorge_mandl@yahoo.com

\section{Editorial}

Volume 4 Issue 4

Received Date: August 03, 2021

Published Date: August 11, 2021

DOI: $10.23880 /$ jqhe-16000235

\section{Editorial}

The COVID-19 pandemic has put enormous pressure on countries around the world, exposing long-standing gaps in public health and exacerbating chronic structural inequalities that, coupled with fragile health systems, have disrupted lives and radically altered the political landscape, especially for vulnerable groups. On the other hand, measures taken to mitigate its impact have highlighted the links between public health and the quality of our environment, our income and work, transport choices, how our children learn, air quality and social justice $[1,2]$.

To counter this, governments and the international community must take responsibility to intervene beyond the sector, and beyond the usual ways of working in health, through a renewed focus on primary health care (PHC) with an emphasis on interactions on the social determinants of health; while civil society and social movements also have a role to play as architects of health and the social services that contribute to achieving it $[3,4]$.

We need to transform this vision into a practical reality: the current focus on integrating wellbeing into policy could be seen as a way of incorporating the social determinants of health into policy at the highest possible level. Investing in primary care will therefore contribute to tangible improvements in health and wellbeing and drive progress towards achieving the health targets of the Sustainable Development Goals [5].

In this regard, we need to ensure that, when planning for recovery from this pandemic, or preparing for future public health emergencies, we keep in mind four key pillars [6]: 1) Health equity with universal coverage. This means giving greater opportunities to vulnerable populations so that there is equal access to available resources and the design of non-discriminatory health policies for the benefit of all citizens; 2) Priority to the person in the provision of services. It is much more important to know what type of person has a disease than what type of disease a person has; 3) Establishing public policies for health and wellbeing. Renewed primary care advocates the creation of systematic public policies, involving public health and non-health sectors, that take into account the health of the population; and 4) Effective leadership and governance. Effective leadership increasingly depends on mediating the complex health challenges of the present and future through a social contract between public, private and wider societal institutions.

A viable approach is offered by the Health in All Policies (HIAP) approach, which encourages to improve the living conditions of disadvantaged people and to cooperate with other policy areas also in complex situations [7]. Extensive evidence shows that this perspective of organisational model and governance styles, together with citizen participation and service reorientation, strengthens the implementation and contributes to the sustainability of Primary Health Care [8].

We conceptualise "Health in All Policies" as a management model characterised by the sequence of integrated and sustained responses in all state policies, the product of multisectoral and transdisciplinary processes of social mediation with the aim of ensuring that all members of society have fair and equitable opportunities to participate in decisions that facilitate changes in their quality of life and health; through a significant transformation in the forms of interaction between political actors, community groups or networks and institutions, within a common historicalcultural environment, whose dynamics and interrelationship produce positive impacts on health while contributing to the achievement of central objectives in other sectors and policy areas [9]. 


\section{Conclusion}

Achieving health and well-being in post-pandemic times requires a renewed focus on primary health care anchored in the political, economic, environmental and social determinants of health; the empowerment of citizens and communities; and; a strong public health system that ensures comprehensive and integrated care. Now more than ever, interconnected reforms are needed to facilitate healthy, inclusive, participatory and accountable public policies across all sectors.

\section{References}

1. Paramoer L, Nandi S, Serag H, Baum F (2021) Covid-19 pandemic and the social determinants of health. BMJ 372: n129.

2. Health in All Policies Team, Community \& Public Health (2020) Pandemic supplement: integrated planning guide for a healthy, sustainable and resilient future. Christchurch, New Zealand: Canterbury District Health Board.

3. Buse K, Nilo A, Kim J, Heywood M, Acaba J (2020) COVID-19 combination prevention requires attention to structural drivers. Lancet 396: 466.

4. Prasad V, Sri BS, Gaitonde R (2020) Bridging a false dichotomy in the COVID-19 response: a public health approach to the 'lockdown' debate. BMJ Glob Health 5: e002909.

5. Morrison V, Lucyk K (2021) Build Back Better: Wellbeing Budgets for a Post COVID-19 Recovery?. Quebec, Canada: National Collaborating Centre for Healthy Public Policy.

6. Brommet A, Lee J, Serna JA (2011) Atención primaria: Una estrategia renovada. Colomb Med 42: 379-387.

7. Blättner B (2020) Covid-19 und gesundheitliche Ungleichheit: Die Relevanz des HiAP-Ansatzes bei Pandemien. Public Health Forum 28(3): 182-184.

8. Herriot M, Valentine NB (2018) Health in All Policies as part of the primary health care agenda on multisectoral action. Geneve: World Health Organization.

9. Mandl Stangl J (2021) Health in All Policies: Management Model for the Comprehensive Transformation of the System. J Qual Healthcare 4(2): 000217. 